\title{
A One-Shot Prisoners' Dilemma with
}

\section{Procedural Utility *}

\author{
Marc Le Menestrel ${ }^{\dagger}$
}

June, 2003

\footnotetext{
*I am especially grateful to C. Loch for the redaction of this paper.

${ }^{\dagger}$ Department of Economics and Business, University Pompeu Fabra, Ramon Trias Fargas 25-27, E-08005 Barcelona. Marc.Lemenestrel@upf.edu
} 


\begin{abstract}
This article introduces a model of rationality that combines procedural utility over actions with consequential utility over payoffs. It applies the model to the Prisoners' Dilemma and shows that empirically observed cooperative behaviors can be rationally explained by a procedural utility for cooperation. The model characterizes the situations in which cooperation emerges as a Nash equilibrium. When rational individuals are not solely concerned by the consequences of their behavior but also care for the process by which these consequences are obtained, there is no one single rational solution to a Prisoners' Dilemma. Rational behavior depends on the payoffs at stake and on the procedural utility of individuals. In this manner, this model of procedural utility reflects how ethical considerations, social norms or emotions can transform a game of consequences.
\end{abstract}

Keywords:

Prisoner's Dilemma; Rationality; Procedural Utility; Social Norms; Ethics; Emotions.

JEL Classification:

A13; C72. 


\section{Introduction}

This paper models how cooperation can arise as an equilibrium in a oneshot Prisoners' Dilemma game under complete information. Game theorists have long searched to reconcile rational behavior with cooperation in a oneshot Prisoners' Dilemma. While economic analysis identifies defection as the only Nash Equilibrium, both cooperative and defective behaviors occur in real life as well as in laboratory experiments, even in one-shot settings. The personality of individuals as well as the social context in which they act influence their behavior (Rapoport 1974, Frank 1988, see Sally 1995 for a review of experimental evidence).

A common approach has been to consider repetitions of the game. Cooperation can be sustained on the basis of infinite repetitions (this is known as the "folk theorem," Kuhn 1953). On the basis of finite repetitions, cooperation can also be sustained provided the players have only incomplete information (Kreps et al. 1982). Harrington (1995) extended the argument to "indirect" repetition, where cooperation may be efficient if agents meet subgroups of their peers at random, without knowing their history of behavior in previous encounters. Another approach to the problem as one of

evolutionary fitness has shown that cooperation can be sustained among a subgroup of the population if some agents recognize habitual "defectors" 
when they see them (e.g., Trivers 1971, Vogt 2000).

While a better understanding of cooperative behaviors has resulted from these approaches, none of them models a truly one-shot game (Harrington 1995). None of them can account for consistent experimental evidence that many individuals cooperate in singular encounters. Moreover, cooperation became stronger in experiments if participants first had the chance to build a "relationship" (without ever meeting again after the game was played, see Frank 1988, p. 142). It is a common informal argument that observed cooperative behavior in the Prisoners 'Dilemma reveals that individuals do not actually play a Prisoners' Dilemma. Indeed, experimental findings suggest that beyond their material good, rational individuals also have "subjective", "ethical" or "emotional" considerations. Individuals may have intrinsic preferences for being fair, for being honest, for reciprocity, etc. (e.g., Rabin 1993, Tooby and Cosmides 1994), which may be justified, for example, by past experiences, by collective outcomes, by cultural norms or by instinctive emotional affects. Even in a one-shot game, such preferences may transform the Prisoners' Dilemma into a new game with new solutions. The problem is that these preferences have generally been viewed as lying outside of rationality. Indeed, the transformation of "material outcomes" by "subjective", "ethical" or "emotional" has not yet been modelled. In the words of Rabin (1993, p. 1285): "Could these [fairness] emotions be directly modeled by 
transforming the payoffs, so that one could analyze this transformed game in the conventional way? This turns out to be impossible" (see also Gilboa and Schmeidler 1988, Geanakoplos and Pearce 1989).

This article however models both the game of observed payoffs and the transformed game as perceived by the players if one appropriately extends the standard solution concepts of game theory towards procedural considerations. The key notion is that rational individuals have utility for the consequences of their actions (the payoffs), but also over the actions themselves, as processes. This means that a rational individual may choose one behavior over another because of its procedural utility, foregoing some material gain. In a Prisoners' Dilemma, for instance, cooperating to reach a given amount of money may be preferred to defecting for the same, or even a larger, amount. The utility from cooperating and earning a given payoff is modeled as the utility of this payoff weighted by the procedural utility of cooperating. In this manner, it is possible to relate the game transformed by procedural utility to the game whose payoffs can be observed: the Prisoners' Dilemma of consequences.

This approach differs from Simon's notion of "procedural rationality" (1976, 1978) developed in a game-theoretic context by Osborne and Rubinstein (1999). Simon considers the procedure by which individuals decide how to act, before the action happens. He does not consider intrinsic preferences for actions themselves. In contrast, the current article starts with the premise 
that behavior is composed of two interdependent but distinct entities, an action and a consequence, and introduces two separate notions of utility, one over each type of entity.

The idea that procedural utility can explain departures from standard interpretations of rationality is not new. For example, Weber (1978, p. 24) considers a type of rationality where behavior is also valued for its own sake because of some "ethical," "aesthetic" or "religious" considerations, "without consideration of success." The notion of procedural utility has received recent attention (e.g. Frey et al. 2002; Frey and Stutzer 2002) but still awaits a proper theoretical foundation. A recurrent idea is that procedural considerations cannot be simply combined with consequential judgments (and thus within the utility function) without weakening the meaning of the utility function (e.g. Harsanyi 1993) or the basic properties of preferences (e.g. completeness in Sen 1997). For Hammond (1988, 1996), consequentialism is indeed necessary to game theory but these authors do not consider the possibility of treating procedural utility outside the utility function. In the context of expected utility theory and in search of a model for the utility of gambling, Le Menestrel (2001) introduces a first model of procedural utility by treating it as a qualitative argument outside the utility function. Further measuring procedural utility as a quantitative multiplicative factor outside the utility function over consequences is then explored as a "mathe- 
matical suggestion" in a following work (Le Menestrel and Van Wassenhove 2001, sec. 5). Recently, a first measurement theoretic result confirms the idea that procedural concerns could be adequately modelled as a multiplicative factor (Le Menestrel and Lemaire 2003). Still, we have no axiomatic foundation for the model of the present paper. On the other hand, no other model has been proposed to specifically study procedural utility in game theory, with or without axiomatic justifications. This paper fills this gap and shows that treating procedural utility as a multiplicative factor outside the utility function over consequences provide for a simple model to explain empirically observed behavior. Because procedural utility is separated from the consequences, it allows to distinguish the game of payoffs presented to the individuals from the psychological game that is perceived, and played.

The paper is structured as follows. Section 2 presents the model and introduces the basic solution concepts of dominance and Nash Equilibrium when procedural utility is considered. Section 3 applies the model to the Prisoners' Dilemma and shows how procedural utility and consequential utility combine to form equilibria. The last section discusses the model and its proposed applications and developments. 


\section{Procedural Utility in Games}

\subsection{Procedural Utility and Consequential Utility}

Consider the simple decision tree in Figure 1. The individual can take action $a_{i}$ to get consequence $c_{i}$. Actions link an individual to consequences. Call a couple composed of an action and its consequence a behavior. Denoting an action by $a \in A$ and a consequence by $c \in C$, the relationship between actions and consequences is reflected by a consequence function $g$ with domain $A$ and range $C, g: A \rightarrow C, a \mapsto g(a)=c$. The consequence function specifies the dependence between consequences and actions. A couple $(a, g(a))$ belongs to the set $B$ of behaviors, which is included in the Cartesian product of the set $A$ of actions and the set $C$ of consequences: $B \subset A \times C$, and $b=(a, g(a)) \in B$. Let us now turn to the notion of utility over these entities.

Individuals are assumed to have separate utility over consequences and over actions. Consequential utility is reflected by a consequential utility function $u()$ over the set $C$. Consequential utility reflects the extent to which a consequence is valued independently of the action (and of other consequences). Procedural utility is reflected in a weighting function $\alpha(), 0 \leqslant$ $\alpha() \leqslant 1, \sum_{A} \alpha(a)=1$ over the set of actions $A$. Procedural utility reflects how an action is valued independently of consequences but relative to other actions. Thus, procedural utility may depend on the set $A$ of actions that 
are available. The modeling of procedural utility as a weight outside the utility function reflects its separation as an intrinsic form of utility from the extrinsic consequential utility.

To summarize, the model highlights two separate influences on rational behavior, which interact in motivating rational decisions. This leads to the following definition:

Definition 1 An individual is acting rationally if and only if he takes action $a^{*} \in A$ such that, for all $a \in A: \alpha\left(a^{*}\right) \times u\left(g\left(a^{*}\right)\right) \geqslant \alpha(a) \times u(g(a))$.

This model has three limiting cases linking it to previous models. First, when procedural utility is neutral, i.e. when the individual does not favor any action intrinsically over any other, rational behavior and consequential behavior coincide. In such situations, the model presented here becomes equivalent to classical game theory. Second, when all outcomes are valued equally, only procedural utility matters. Third, when procedural utility weights only one action $(\alpha(a)=1)$, then such an action is implemented whatever the consequence it leads to. This case was called value-rational by Weber to characterize rational behaviors that are not motivated by consequences at all (Weber 1978, p. 24-26). An act of revenge and, at the extreme, the voluntary sacrifice of one's own life are typical examples (e.g., Frank 1988, 43).

Let us summarize these features of the model in the following properties, 
denoting $\left(a^{*}, g\left(a^{*}\right)\right)$ the rational behavior.

Property 1 [Neutrality of procedural utility]. If $\alpha(a)=\alpha \neq 0$ for all $a \in$ $A$, then $u\left(g\left(a^{*}\right)\right) \geqslant u(g(a))$.

Property 2 [Neutrality of consequential utility]. If $u(g(a))=C t e$ for all $a$ $\in A$, then $\alpha\left(a^{*}\right) \geqslant \alpha(a)$.

Property 3 [Value-rationality]. If $\alpha(a)=1$ then $a=a^{*}$.

The model allows us to identify a "best possible" case, where no dilemma arises between actions and consequences. When a procedurally preferred action leads to the preferred consequence, the behavior composed of such a combination is called ideal. It is ideal to choose such a behavior but a chosen behavior may not be ideal.

Property 4 [Ideal Behavior]. If $\alpha(a) \geqslant \alpha\left(a^{\prime}\right)$ and $u(a) \geqslant u\left(a^{\prime}\right)$ then $\alpha(a) \times$ $u(g(a)) \geqslant \alpha\left(a^{\prime}\right) \times u\left(g\left(a^{\prime}\right)\right)$.

\subsection{Procedural and Consequential Utility in Games}

We now develop the model in the context of game theory. Game theory considers only utility over consequences (Osborne and Rubinstein 1994, p. 4). However, it is possible to integrate procedural utility in the solution concepts of game theory by specifying both action and consequence in the definition 
of a behavior. In particular, the solution concept of Nash Equilibrium can be formulated such that it integrates procedural utility.

Formally, refer to individual $i$ as a member of a set $N$ of $n$ individuals. Individual $i$ takes an action $a_{i}$ belonging to the set $A_{i}$ of all actions available to him. Denote an action profile by $a=\left(a_{1}, \ldots, a_{n}\right)$, or equivalently $a=$ $\left(a_{i}, a_{-i}\right)$. The set of actions profiles is the Cartesian product of the sets of the individuals' available actions, $A=\times_{i \in N} A_{i}$. Denote by $g$ a consequence function whose domain is the set of profiles of actions and whose range is the set of interdependent consequences $C$. The consequence of actions profile $a$ is $g(a) \in C$. The definition of a behavior remains as before, namely the couple of an action and its consequence, only that the consequence depends also on the actions of the other players. A behavior is denoted by $\left(a_{i}, g\left(a_{i}, a_{-i}\right)\right)$. The set of behaviors for individual $i$ is denoted $B_{i} \subset A_{i} \times C$ and one of its members $b_{i}=\left(a_{i}, g\left(a_{i}, a_{-i}\right)\right), b_{i} \in B_{i}$. Now, we can define a Nash Equilibrium with procedural utility and consequential utility:

Definition 2 (Nash Equilibrium with Procedural Utility.) A profile of actions $a^{*}=\left(a_{i}^{*}, a_{-i}^{*}\right)$ is a Nash Equilibrium if and only if, for all $i \in N: \forall$ $a_{i} \in A_{i}, \alpha_{i}\left(a_{i}^{*}\right) \times u_{i}\left(g\left(a^{*}\right)\right) \geqslant \alpha_{i}\left(a_{i}\right) \times u_{i}\left(g\left(a_{i}, a_{-i}^{*}\right)\right)$.

To clarify the significance of this definition, let us compare it to the traditional definition used in game theory. When procedural utility is not 
considered, a profile of actions is a Nash Equilibrium if and only if, for all $i \in N, \forall a_{i} \in A_{i}, u_{i}\left(g\left(a_{i}^{*}, a_{-i}^{*}\right)\right) \geqslant u_{i}\left(g\left(a_{i}, a_{-i}^{*}\right)\right)$. The two definitions are equivalent in case of neutral procedural utility. As we argued earlier, the traditional interpretation of game theory appears as a limit-case implicitly assuming that individuals have no procedural utility.

As we have discussed an "ideal" behavior for a single individual, we can use the same concept in order to single out one Nash Equilibrium that is preferred for both its action and its consequence. Consider a situation where, for all individuals, the action with the highest procedural utility leads to the consequence with the highest consequential utility (given the other players' actions). Individuals would implement the action with the highest procedural utility and would not regret it ex post. we propose to call such a 'focal' or 'salient' equilibrium an Ideal Nash Equilibrium. Formally, denoting with $A^{*}$ the set of profiles of actions that are Nash Equilibria, we can define an Ideal Nash Equilibrium as follows:

\section{Definition 3 (Ideal Nash Equilibrium with Procedural Utility) .}

A profile of actions $\bar{a}^{*}=\left(\bar{a}_{i}^{*}, \bar{a}_{-i}^{*}\right)$ is an Ideal Nash Equilibrium if and only if, $\forall i \in N$ and $\forall a^{*} \in A^{*}, u_{i}\left(g\left(\bar{a}^{*}\right)\right) \geqslant u_{i}\left(g\left(a^{*}\right)\right)$ and $\forall a_{i} \in A_{i}, \alpha_{i}\left(\bar{a}_{i}^{*}\right) \geqslant \alpha_{i}\left(a_{i}\right)$.

An Ideal Nash Equilibrium does not always exist. However, when it exists, it has two simple but important properties: 
Proposition 4 An Ideal Nash Equilibrium with strictly greater procedural utility or strictly greater consequential utility is unique.

Proof. To show this property, consider first the case of strictly greater consequential utility, i.e.: $\forall a^{*} \in A^{*}, u_{i}\left(g\left(\bar{a}^{*}\right)\right)>u_{i}\left(g\left(a^{*}\right)\right)$. If there was another Ideal Nash Equilibrium, say $\tilde{a}^{*}=\left(\tilde{a}_{i}^{*}, \tilde{a}_{-i}^{*}\right)$, then we would have $\forall a^{*} \in A^{*}, u_{i}\left(g\left(\tilde{a}^{*}\right)\right) \geqslant u_{i}\left(g\left(a^{*}\right)\right)$. Thus, taking $a^{*}=\bar{a}^{*}$, we would have $u_{i}\left(g\left(\tilde{a}^{*}\right)\right) \geqslant u_{i}\left(g\left(\bar{a}^{*}\right)\right)$, which contradicts the assumption of strictly greater consequential utility. Now consider strictly greater procedural utility, i.e.: $\forall a_{i} \in A_{i}, \alpha_{i}\left(\bar{a}_{i}^{*}\right)>\alpha_{i}\left(a_{i}\right)$. If there was another Ideal Nash Equilibrium, say $\tilde{a}^{*}$, then we would have $\forall a_{i} \in A_{i}, \alpha_{i}\left(\tilde{a}_{i}^{*}\right) \geqslant \alpha_{i}\left(a_{i}\right)$. Thus, taking $a_{i}=\bar{a}_{i}^{*}$, we would have $\alpha_{i}\left(\tilde{a}_{i}^{*}\right) \geqslant \alpha_{i}\left(\bar{a}_{i}^{*}\right)$, which contradicts strictly greater procedural utility.

The second property links the Ideal Nash Equilibrium to the concept of a Pareto-efficient Equilibrium.

Proposition 5 An Ideal Nash Equilibrium is always a Pareto-efficient equilibrium.

Proof. To show this property, we first recall that a Pareto-efficient Equilibrium corresponds to the best equilibrium individuals can reach. Considering also procedural utility, a profile of actions $\tilde{a}^{*}$ is a Pareto-efficient Equilibrium when, for all $i$, and all $a^{*} \in A^{*}$, we have $\alpha_{i}\left(\tilde{a}_{i}^{*}\right) \times u_{i}\left(g\left(\tilde{a}^{*}\right)\right) \geqslant \alpha_{i}\left(a_{i}^{*}\right) \times$ 
$u_{i}\left(g\left(a^{*}\right)\right)$. If a profile of actions $\bar{a}^{*}$ is an Ideal Nash Equilibrium, then for all individuals, $\alpha_{i}\left(\bar{a}^{*}\right) \geqslant \alpha_{i}\left(a_{i}\right)$ and $u_{i}\left(g\left(\bar{a}^{*}\right)\right) \geqslant u_{i}\left(g\left(a^{*}\right)\right)$. We have, therefore, $\alpha_{i}\left(\bar{a}_{i}^{*}\right) \times u_{i}\left(g\left(\bar{a}^{*}\right)\right) \geqslant \alpha_{i}\left(a_{i}^{*}\right) \times u_{i}\left(g\left(a^{*}\right)\right)$.

As a result, the concept of Ideal Nash Equilibrium enables us to select one single equilibrium among several ones. It provides a possible criterion to single out the 'focal' or 'salient' equilibrium in case of coordination issues (Schelling 1980). Moreover, it sheds light on how individuals may reach Pareto-efficient equilibria. These concepts and properties are now applied to the Prisoners' Dilemma.

\section{Application of procedural Utility to the One- Shot Prisoners' Dilemma}

\subsection{Specification of the Game}

Following the approach developed in the preceding section, we can now formalize the idea that the game played by the individuals is not merely a game of consequences. Suppose the players in the Prisoners' Dilemma have a procedural utility to cooperate. The proposed approach encompasses social context considerations that were previously excluded (Schelling 1980, p. 180 and 285). This allows us to interpret cooperative behavior in the Prison- 
ers' Dilemma as revealing procedural utility, caused by, for example, a social norm for cooperation.

We will now show that for a low procedural utility, the behavioral game remains such that mutual defection is the only equilibrium. When both individuals have higher procedural utility, the behavioral game become a coordination game, where mutual defection and mutual cooperation are both Nash Equilibria (although mutual cooperation is the Ideal Nash Equilibrium). Finally, when both individuals have even higher procedural utility, mutual cooperation becomes the only equilibrium (and the Ideal Nash Equilibrium).

We specify a two-individual Prisoners' Dilemma with perfect information and procedural utility in the following way:

(i) $N=\{1,2\}$ is the set of individuals.

(ii) Two actions are available for each individual: $A_{i}=\{C o, D e\}, i \in N$. Possible actions profiles are $(C o, C o),(C o, D e),(D e, C o)$, and $(D e, D e)$. The first action is attributed to individual $i$ and the second to individual $-i$. Behaviors of individual $i$ are $(C o, g(C o, C o)),(C o, g(C o, D e)),(D e, g(D e, C o))$, and $(D e, g(D e, D e))$.

(iii) Individual $i$ 's consequential utility is given by: 


$$
\begin{aligned}
u_{i}(g(D e, C o)) & =w_{i}(i \text { defects but }-i \text { cooperates }) \\
u_{i}(g(C o, C o)) & =x_{i}(\text { both cooperate }) \\
u_{i}(g(D e, D e)) & =y_{i}(\text { both defect }) . \\
u_{i}(g(C o, D e)) & =z_{i}(i \text { cooperates but }-i \text { defects })
\end{aligned}
$$

The characteristics of a Prisoner's Dilemma game are that $w_{i}>x_{i}>y_{i}>$ $z_{i}$. We further require $z_{i}>0$. The strict ordering ensures that any ideal Nash Equilibrium is unique (Proposition 4). The game of consequences can be represented in its normal form by the following matrix, where actions of individual 1 are stated in the rows and actions of individual 2 in the columns. In each box, consequential utility of individual 1 is stated first:

\begin{tabular}{|c|c|c|}
\hline & Cooperation $(C o)$ & Defection $(D e)$ \\
\hline Cooperation $(C o)$ & $x_{1}, x_{2}$ & $z_{1}, w_{2}$ \\
\hline Defection $(D e)$ & $w_{1}, z_{2}$ & $y_{1}, y_{2}$ \\
\hline
\end{tabular}

Table 4.1: The Prisoners' Dilemma of Consequences

(iv) Individual $i$ 's procedural utility is given by: 


$$
\alpha_{i}:\left\{\begin{array}{l}
\alpha_{i}(C o)=\alpha_{i} \\
\alpha_{i}(D e)=1-\alpha_{i}
\end{array} \quad \text { with } \frac{1}{2} \leqslant \alpha_{i}<1 .\right.
$$

The condition $\frac{1}{2} \leqslant \alpha_{i}<1$ restricts the game to situations where individuals have procedural utility for cooperation (with disutility for cooperation, the cooperative Nash Equilibrium disappears and the result with value rationality, $\alpha_{i}=1$, is trivial).

(v) We can now represent the game as it is perceived by the players, including procedural concerns:

\begin{tabular}{|c|c|c|}
\hline & Cooperation $(C o)$ & Defection $(D e)$ \\
\hline Cooperation $(C o)$ & $\alpha_{1} \times x_{1}, \alpha_{2} \times x_{2}$ & $\alpha_{1} \times z_{1},\left(1-\alpha_{2}\right) \times w_{2}$ \\
\hline Defection $(D e)$ & $\left(1-\alpha_{1}\right) \times w_{1}, \alpha_{2} \times z_{2}$ & $\left(1-\alpha_{1}\right) \times y_{1},\left(1-\alpha_{2}\right) \times y_{2}$ \\
\hline
\end{tabular}

Table 4.2: The Prisoners' Dilemma transformed by procedural Utility

\subsection{Existence of Nash Equilibria}

The Nash Equilibria of this game depend both on the consequential utilities $w_{i}, x_{i}, y_{i}, z_{i}$ and on the individual procedural utility for cooperation $\alpha_{i}$. Applying definition 2 for the profile of actions $(\mathrm{Co}, \mathrm{Co})$, cooperation for both individuals is a Nash Equilibrium if and only if: 


$$
\begin{aligned}
\forall i \quad & \quad N, \alpha_{i}(C o) \times u_{i}(g(C o, C o)) \geqslant \alpha_{i}(D e) \times u_{i}(g(D e, C o)) \\
& \Longleftrightarrow \alpha_{1} \geqslant \frac{w_{1}}{w_{1}+x_{1}} \text { and } \alpha_{2} \geqslant \frac{w_{2}}{w_{2}+x_{2}} .
\end{aligned}
$$

Similarly, $(D e, D e)$ is a Nash Equilibrium if and only if:

$$
\alpha_{1} \leqslant \frac{y_{1}}{y_{1}+z_{1}} \text { and } \alpha_{2} \leqslant \frac{y_{2}}{y_{2}+z_{2}}
$$

This game may also include asymmetric equilibria. Individual $i$ chooses action $C o$ while individual $-i$ chooses $D e$, that is, $(C o, D e)$ is a Nash Equilibrium, if and only if:

$$
\alpha_{i} \geqslant \frac{y_{i}}{y_{i}+z_{i}} \text { and } \alpha_{-i} \leqslant \frac{w_{-i}}{w_{-i}+x_{-i}}
$$

Having determined the conditions for the existence of Nash Equilibria, let us now examine when multiple equilibria coexist. Condition (9) is incompatible both with (7) and (8). Thus, asymmetric equilibria cannot coexist with symmetric equilibria. However, the symmetric equilibria $(C o, C o)$ and $(D e, D e)$ 
may coexist under the following conditions:

$$
\frac{y_{i}}{y_{i}+z_{i}} \geqslant \alpha_{i} \geqslant \frac{w_{i}}{w_{i}+x_{i}}, \forall i \in N
$$

The asymmetric equilibria $(C o, D e)$ and $(D e, C o)$ can also coexist, provided

$$
\frac{w_{i}}{w_{i}+y_{i}} \geqslant \alpha_{i} \geqslant \frac{y_{i}}{y_{i}+z_{i}}, \forall i \in N
$$

When it exists, the equilibrium $(\mathrm{Co}, \mathrm{Co})$ is always the Ideal Nash Equilibrium. It can coexist only with $(D e, D e)$, which cannot be ideal while coexisting with $(C o, C o)$. This is because $\alpha_{i} \geqslant \frac{w_{i}}{w_{i}+x_{i}}>\frac{1}{2}, \forall i$ by the definition of the Prisoner's Dilemma consequential utility and by formula (7). Therefore, $\alpha_{i}(C o)>\alpha_{i}(D e)$. Since we have also $u_{i}(g(C o, C o)) \geqslant u_{i}(g(D e, D e))$ by the Prisoner's Dilemma payoff structure, $(C o, C o)$ is the only Ideal Nash Equilibrium.

Asymmetric Nash Equilibria are never ideal in this game because the procedural condition $\alpha_{i}(D e)>\alpha_{i}(C o)$ is not satisfied for the player who chooses defection. Finally, $(D e, D e)$ is the Ideal Nash Equilibrium if and only if $\alpha_{i}=\frac{1}{2}$. 


\subsection{Graphical Illustration of the Equilibria}

Figures 2 through 4 graphically illustrate the existence of the different Nash Equilibria and their ideality, using the procedural utility for cooperation $\alpha_{1}$ and $\alpha_{2}$ of individuals 1 and 2 as coordinates. As is discussed above, the procedural utility parameters have a range from $1 / 2$ to 1 . The case $\alpha_{i}=1 / 2$ corresponds to neutral procedural utility and $\alpha_{i}=1$ to valuerationality (property 3 page 10). The three figures show three scenarios, corresponding to different combinations of (7) through (9).

Case 1, shown in Figure 2. is characterized by $\frac{y_{i}}{y_{i}+z_{i}} \geqslant \frac{w_{i}}{w_{i}+x_{i}}$ for all individuals $i$. This condition says that the relative benefit of defection over cooperation is bigger when the other also defects than when the other cooperates. To give an example, this condition is fulfilled when $w=10, x=6$, $y=2$ and $z=1$. When the other side defects, defecting increases consequential utility by a factor of five-to-one while the increase is by a factor of two-to-one when the other side cooperates. Under the general condition of case 1, a Nash Equilibrium always exists. Symmetric equilibria of cooperation and defection can coexist, but as we have shown, only the cooperation equilibrium is ideal. At each asymmetric corner, there exists an asymmetric equilibrium. It is not ideal for either player. For low $\alpha_{1}$ and $\alpha_{2}$, only the Defection equilibrium remains, which is never ideal, except for the limit-case 
of procedural neutrality of all individuals. As soon as individuals have an arbitrary low procedural utility for cooperation, the Defection equilibrium loses its ideality property.

Case 2, shown in Figure 3, is the "opposite" of Figure 2 in the sense that the relative benefit from defection is bigger when the other side cooperates. In the context of the numerical example from Case 1, this condition is fulfilled when the payoff $x$ (mutual cooperation) is reduced to 4: now, the benefit from defecting over cooperating remains at two-to-one when the other side defects, but has increased to five-to-two when the other side cooperates. Thus, some individuals who cooperated in case 1 no longer cooperate in case 2 (keeping procedural utility unchanged).

In this case, the player who cooperates, but faces defection from the other player, has a smaller incentive to switch to defection than in case 1. A Nash Equilibrium always exists, but the reduced defection incentive causes asymmetric equilibria to coexist at intermediate procedural utility levels. The symmetric and ideal equilibrium of cooperation is restricted to higher procedural utility than in Case 1. The symmetric equilibrium of defection holds for symmetrical procedural utility values close to neutrality but, as discussed above, never coexists with the cooperation equilibrium. At each asymmetric corner, one asymmetric equilibrium exists similarly to Case 1. 
Case 3, shown in Figure 4, illustrates what happens when cases 1 and 2 are "mixed": player 1 faces a higher relative benefit from defection when player 2 defects, and player 2 faces a higher relative benefit from defection when player 1 cooperates (of course, the roles of two players can be exchanged). While strong procedural utility for cooperation still drive the equilibria (as in Cases 1 and 2), this asymmetry prevents existence of any Nash Equilibrium for intermediate procedural utility levels.

\section{Conclusion}

This paper proposed to model the notion of procedural utility with an application to game theory. Behaviors are defined as couples composed of an action and its consequence according to a consequence function. The decision maker has utility not only over consequences, as traditionally modeled, but also intrinsic utility over actions themselves.

In this richer structure, the proposed model extends the solution concept of Nash Equilibrium to include ethical or emotional motivations that are beyond the sole pursuit of consequences. This refinement of the Nash Equilibrium concept allows us to distinguish "better" and "worse" equilibria in a game: an "ideal" Nash Equilibrium is composed of actions that have the highest procedural utility and of consequences that have the highest conse- 
quential utility at equilibrium.

Procedural utility models the transformation of a game of consequences and offers an explanation for consistent cooperation in experiments with anonymous one-shot Prisoners' Dilemma games. Mutual cooperation can emerge as the unique Ideal Nash Equilibrium when procedural utility for cooperation is sufficiently strong. Moreover, we can characterize all existing Nash Equilibria in the game, depending on the payoff structure and on the strength of procedural utility.

The conventional interpretation of a Prisoners' Dilemma is that individuals should defect, whatever the payoff differentials between cooperation and defection. In the current model, procedural utility may allow individuals to reach a cooperative equilibrium, although such an equilibrium is not sustained if the payoff differential from defecting is too much increased. Moreover, a given game of consequences may be played differently by different individuals with different procedural utility. The results of the model allow predictions about the dependence of rational behavior upon individuals and upon the social context. These predictions may be tested in experiments on collaborative behavior.

Thus, this article may contribute to recent work in economics that has incorporated issues not related to the consumption of material goods, such as intrinsic motivations (Frey 1997), status (Frank 1988, Robson 1992, Loch 
et al. 2000), friendship (e.g., Trivers 1971, Tooby and Cosmides 1994, Bester and Güth 1998), or social norms (Kandori 1992). The notion of procedural utility may contribute to widening the scope of game theory into psychological and social phenomena.

\section{References}

Bester, H., Güth, W. (1998). Is altruism evolutionarily stable? Journal of Economic Behavior and Organization 34, pp. 193 - 209.

Frank, R.H. (1988). Passions within Reason: The Strategic Role of the Emotions. Norton, New York.

Frey, B. S. (1997). Not Just for the Money: An Economic Theory of Personal Motivation. Edward Elgar Publishing. Cheltenham.

Frey, B. S. and Stutzer, A. (2002). Beyond Outcomes: Measuring Procedural Utility. Berkeley Olin Program in Law \& Economics, Working Paper No. 63.

Frey, B. S., Benz, M. and Stutzer, A. (2002). Introducing Procedural Utility: Not only What, but also How Matters. Institute for Empirical Research in Economics, University of Zürich. Working Paper No. 129.

Geanakoplos, J., Pearce D. (1989). Psychological games and sequential rationality. Games and Economic Behavior 1, pp. 60-79.

Gilboa, I., Schmeidler, D. (1988). Information dependent games: can com- 
mon sense be common knowledge? Economic Letters 27, pp. 215-221.

Hammond, P. J.: 1988, 'Consequentialist Foundations of Expected Utility', Theory and Decision, 25, 25-78.

Hammond, P. J.: 1996, 'Consequentialism, Rationality and Game Theory', in Arrow, K.J., Colombatto, E., Perlman, M. and C. Schmidt (eds): 1996, The Rational Foundations of Economic Behaviour, pp. 25-42.Harrington, J.E. (1995). Cooperation in a one-shot Prisoners' Dilemma. Games and Economic Behavior 8, pp. 364-377.

Harsanyi, J. C.: 1993, 'Normative Validity and Meaning of von NeumannMorgenstern Utilities', in Binmore K., Kirman, A. and Tani, P. (eds): 1993, Frontiers of Game Theory, Cambridge \& London, MIT Press, 307-320.

Kandori M., 1992. Social norms and community enforcement. Review of Economic Studies 59, pp. 63 - 80.

Kreps, D., Milgrom, P., Roberts, J., and Wilson, R. (1982). Rational cooperation in the finitely repeated Prisoner's Dilemma. Journal of Economic Theory 27, pp. $253-279$.

Kuhn, H. (1953). Extensive games and the problem of information. In: Contributions to the Theory of Games Vol. 2, H. Kuhn and A. Tucker (Eds.), Princeton University Press, Princeton, NJ, pp. 193 - 216.

Le Menestrel, M. (2001). A Process Approach to the Utility of Gambling. Theory and Decision 50, pp. 249-262. 
Le Menestrel, M. and Van Wassenhove, L., (2001). The domain and interpretation of utility function: An exploration. Theory and Decision, 51, 329-349.

Le Menestrel, M. and Lemaire, B. (2003). Biased Extensive Measurement: The Homogeneous Case. Journal of Mathematical Psychology (Accepted for publication).

Loch, C. H., Huberman, B., Stout, S. (2000). Status competition and performance in work groups. Journal of Economic Behavior and Organization 43, pp. $35-55$.

Osborne, M. J., Rubinstein A. (1994). A Course in Game Theory. MIT Press, Cambridge MA.

Osborne, M. J. Rubinstein A. (1998). Games with procedurally rational players. The American Economic Review 88, pp. 834-847.

Rabin, M. (1993). Incorporating fairness into game theory and economics. The American Economic Review 83, pp. 1281-1302.

Rapoport, A. (1974). Prisoner's Dilemma - Recollections and Observations. In Game Theory as a Theory of Conflict Resolution, A. Rapoport (Ed.), Reidel, Dordrecht.

Robson, A. J. (1992). Status, the Distribution of Wealth, Private and Social Attitudes to Risk. Econometrica 60, pp. 837 - 857.

Sally, D. (1995). Conversation and Cooperation in Social Dilemmas - A 
Meta-Analysis of Experiments from 1958 to 1992. Rationality and Society 7, pp. 58-92.

Schelling, T. C. (1960). The strategy of Conflict, Harvard University, Cambridge MA. Second edition 1980.

Sen, A.: 1997, 'Maximization and the Act of Choice', Econometrica, 65, 745-779.

Simon, H.A. (1976). From substantive to procedural rationality. In Methods and Appraisal in Economics, S. J. Latsis (Ed.), Cambridge University Press, Cambridge MA.

Simon, H.A. (1978). Rationality as process and as product of thought. The American Economic Review 68, pp. 1-16.

Tooby, J. Cosmides, L. (1994). Better than rational : evolutionary psychology and the invisible hand. The American Economic Review 84, pp. $327-332$.

Trivers, R. L. (1971). The evolution of reciprocal altruism. The Quarterly Review of Biology 46, pp. 35 - 57.

Vogt, C. (2000). The Evolution of cooperation in prisoners' dilemma with an endogenous learning mutant. Journal of Economic Behavior \& Organization 42, pp. 347-373.

Weber, M. (1978). Economy and Society: An Outline of Interpretive Sociology. University of California Press, Berkeley. First edition 1922. 


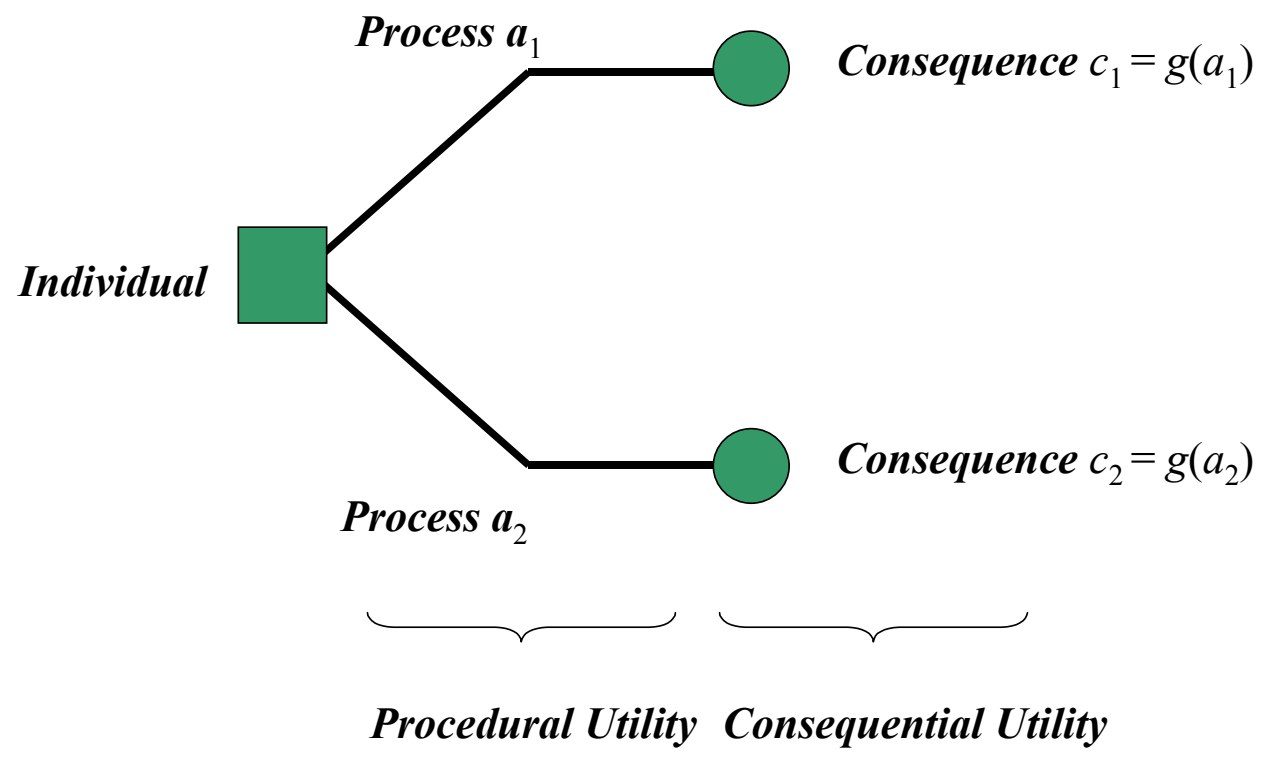

Figure 1: Valuing Processes and Consequences 


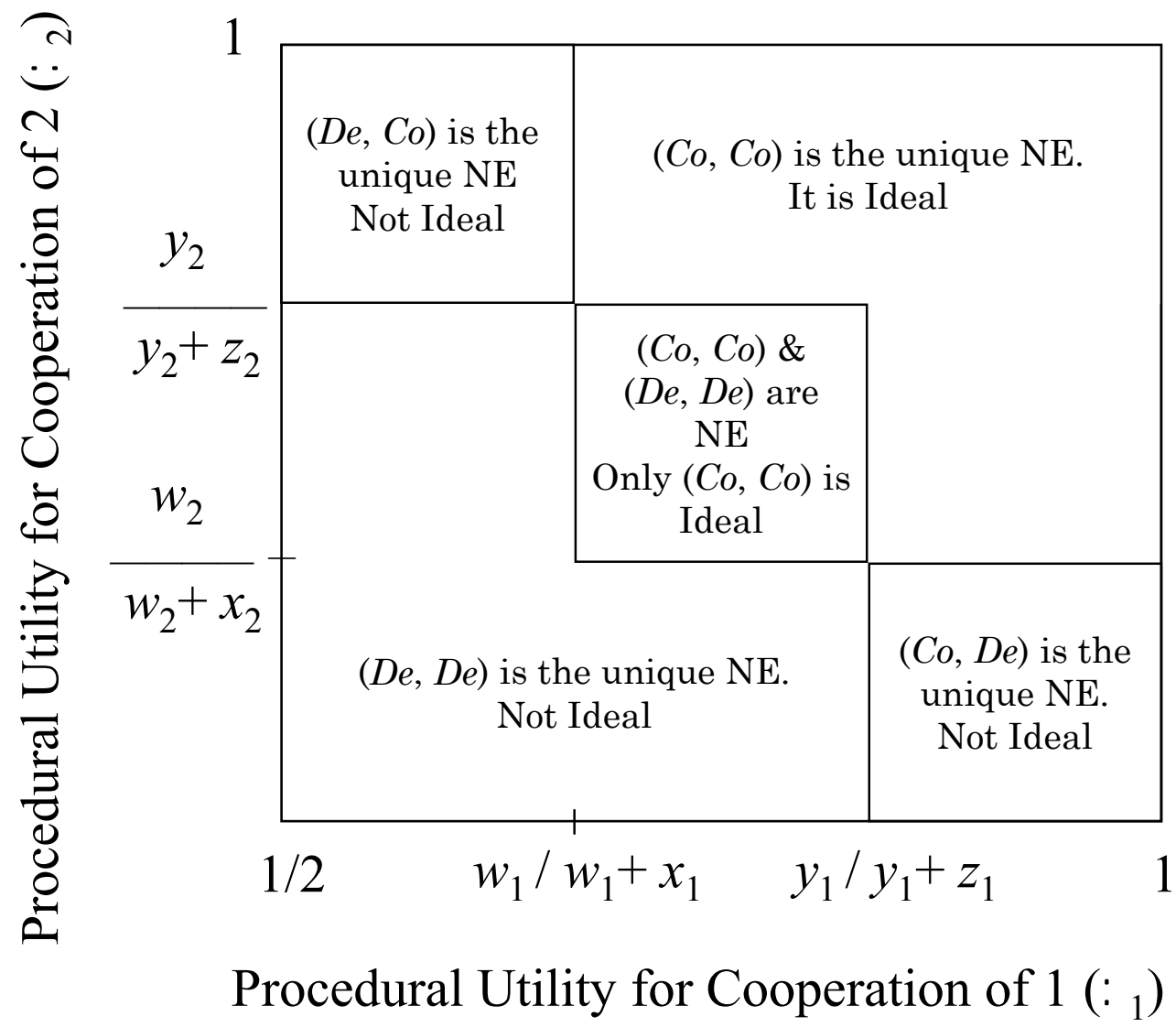

Figure 2: Nash Equilibria with stronger benefit from defection when the other side defects 


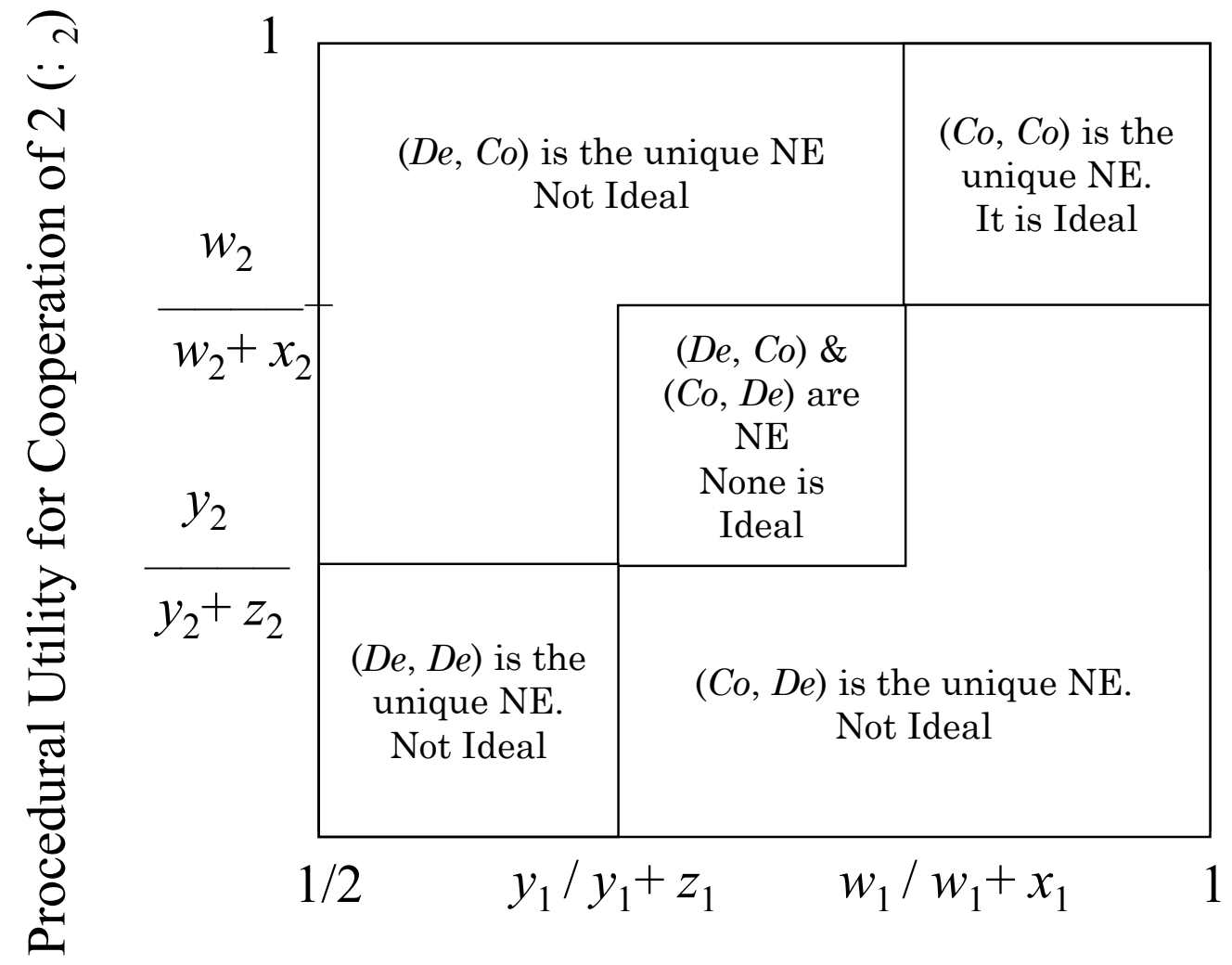

Procedural Utility for Cooperation of 1()$\left._{1}\right)$

Figure 3: Nash Equilibria with stronger benefit from defection when the other side cooperates 


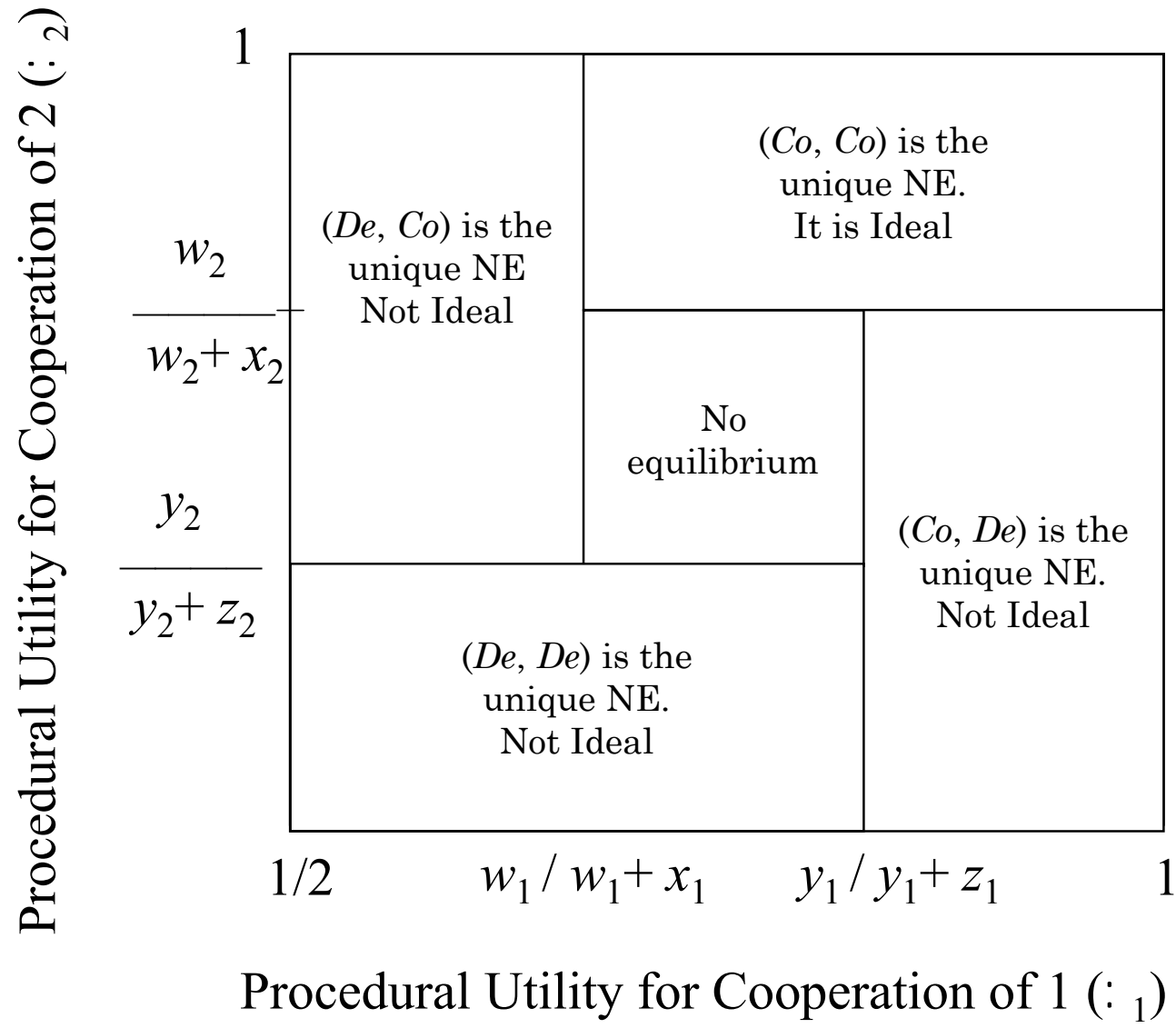

Figure 4: Nash Equilibria with mixed relative benefits from defection 